ORIGINAL ARTICLE

\title{
Variation of Pediatric Doses Undergoing Digital and Computed Radiography Examination in Addis Ababa, Ethiopia
}

\author{
Seife Teferi ${ }^{{ }^{*}}$, Daniel Zewdeneh ${ }^{1}$
}

\section{OPEN ACCESS}

Citation: Seife Teferi, Daniel Zewdeneh. Variation of Pediatric Doses Undergoing Digital and Computed Radiography Examination in Addis Ababa, Ethiopia. Ethiop J Health Sci.2020;30(2):269.doi:http://dx. doi.org/10.4314/ejhs.v30 i2.15 Received: September 3, 2019

Accepted: November 27, 2019

Published: March 1, 2020

Copyright: (C2020 Seife Teferi, et al. This is an open access article distributed under the terms of the Creative Commons Attribution License, which permits unrestricted use, distribution, and reproduction in any medium, provided the original author and source are credited.Funding: AAU and ICTP Competing Interests: The authors declare that this manuscript was approved by all authors in its form and that no competing interest exists.

Affiliation and Correspondence:

${ }^{1}$ Department of Radiology, College of Health Sciences, Addis Ababa University

*Email: seifeteferi@yahoo.com

\begin{abstract}
BACKGROUND: Various researchers who carried out national and international surveys have reported wide variations in patient dose arising from specific $X$-ray examinations. Thus, assessment of radiation dose is an essential part in the optimization process. The aim of this study was to compare the entrance surface doses delivered to pediatric patients undergoing digital and computed radiography $X$-ray examination.

MATERIAL AND METHODS: A cross-sectional study was conducted on 389 pediatric $X$-ray projections less than 15 years of age on eight X-ray machines in Addis Ababa in February 2009 E.C. The tube output of the $X$-ray machines in air was measured using RaySafe XI dosimeters. Then, entrance surface dose was estimated for common $x$-ray examinations like chest, skull, extremities and pelvis using established relation between $X$-ray tube output and radiographic parameters. These data were analyzed statistically using computer (Excel and SPSS method).

RESULT: The third quartile estimated ESDs in mGy for both computed and digital radiography examinations of chest $(A P)$ for age (0-1 year) were 0.24 and 0.15, (1-5 year) 0.3and 0.16. For the age group (5-10 year), it was 1.97 and 0.26 and for the(10-15 year)group, 0.56 and 0.18 respectively. These values were higher than those of the United Nations Scientific Committee's on the Effects of Atomic Radiation's established dose reference levels(in mGy for age (0-1 year) 0.02, (1-5 year) 0.03, (5-10 year) 0.04, and (10-15 year) 0.05 respectively).

CONCLUSION: The wider dose variation between computed and digital radiography shows that there is a pressing need to minimize the detriment caused by unnecessary computed radiography.

KEYWORDS: pediatric radiation dose, computed radiography, digital radiography
\end{abstract}




\section{INTRODUCTION}

The benefits of X-ray examinations are related with patient diagnosis. However, the use is not entirely without risk due to the biological effect of X-rays. It is well known that the risks from ionizing radiation in children are about two to three-fold as compared with adults $(1,2)$. The use of X-rays in medical radiography has continued to increase despite technological advances in other modern imaging techniques.

In many countries, especially in developing countries, conventional radiography is still a dominant diagnostic tool in comparison with other imaging techniques such as CT, or MRI (1-3). The disadvantage of conventional radiography is that if the radiograph is too dark or too light it has to be repeated. When the number of examination increases, there is a possibility of increasing collective doses to the pediatric populations (4).

In conventional radiography, the completion of the examination is delayed as the film has to be processed to convert the latent images into a permanent one. During the past two decades, digital radiography (DR) and computed radiography (CR) have supplanted screen-film radiography in many radiology departments (4-5). Digital detectors allow implementation of a fully digital picture archiving and communication system, in which images are stored digitally and are available anytime. Image distribution in hospitals can now be achieved electronically by means of web-based technology with no risk of losing images (6). Computed radiography is a digital way of doing general radiography with conventional X-ray machines except conventional screen/film and dark room (5). The technical aspects of CR are similar to what one sees in the traditional analog radiology department, i.e., the technologist exposes a cassette that is then processed (5). The limitation of $\mathrm{CR}$ is that radiological technologists receive no direct feedback on the accuracy of their selection of exposure factors. Compensation for under- and over-exposure is a benefit of digital radiographic systems (5). Internal amplification (increased for under-exposure and decreased for over-exposure) results in a similar presentation of the output data that is independent of the incident exposure. Since
$\mathrm{CR}$ enables digital imaging with the same as conventional radiography techniques there may be an increase of pediatric patient doses than DR as seen in $(4,5)$ in Addis Ababa. While both CR and DR have wider dose range and can be post processed to eliminate mistakes and repeat exams, DR improves work flow than CR. As we have seen above both CR and DR have large dynamic ranges, it is relatively easy to over expose the patient. To reduce and estimate radiation doses to the patient, periodic dose assessments should be mandatory in the department of diagnostic radiology (7-9). Hence dose measurements are required further to compare $\mathrm{CR}$ and DR to comply with some international guidelines and regulations.

\section{MATERIALS AND METHODS}

Study design: The study was conducted in Addis Ababa in February 2017G.C.It utilizes a crosssectional study design. Eight X-ray units of the hospitals/clinics were included in the study. Any piece of hospital information was kept confidential by not recording individuals' names. Hence, the hospitals/clinics that participated in the study were thereafter referred as A, B, C, D, E, F, and G. The hospitals/clinics were chosen for the study because of their willingness and variable set up.

Sample Size and Sampling Technique:The sample size was determined based on International Commission of Radiation Protection (ICRP) recommendations. ICRP requires that patient dose surveys should include at least 10 standard sizes patients for each age group from each hospital to conduct such study. To increase precession, a one month data were collected from seven hospital/clinics and eight X-ray units. Accordingly, a total of 389 pediatric radiographic exposures under 15 years of age were included for our research. Fifty-four $(13.9 \%)$ fromhospital A, 102 $(26.22 \%)$ were from hospital B, 53(13.66\%) from hospital C, and42 (10.79) from D, whereas $37(9.5 \%)$ werefrom E, 48(12.3\%) from $\mathrm{F}$ and $53(13.66 \%)$ from $\mathrm{G}$.

Data collection procedure: For each patient, age, sex, weight and type of examination (chest, skull, extremities and pelvis) with their AP, PA and LAT projections were documented in the format. In

DOI: http://dx.doi.org/10.4314/ejhs.v30i2.15 
addition, exposure parameters like tube potential $(\mathrm{kVp})$, tube current $(\mathrm{mA})$, exposure time (sec), and focus to skin distance FSD $(\mathrm{cm})$ were recorded by the radiographers at the time of examination for each patient during exposure. The children were divided into four groups of age intervals $0-1$ year, 1-5 years, 5-10 years and 10-15 years. Since the xray tube at $80 \mathrm{KVp}$ and anode current at $20 \mathrm{mAs}$ were highly stabilized, the tube output measurements were taken by RaySafe Xi digital dosimeters at one meter film focus distance (FFD). By using the tube output and exposure parameters from the data, ESD were calculated by using the equation shown below. In this study, the back scatter factor (BSF) for all patients was taken to be 1.35 as it ranges 1.2-1.5 in diagnostic radiology (9).

$$
E S D=(O / P) X\left(\frac{K V p}{80}\right)^{2} X(m A s)\left(\frac{100}{F S D}\right)^{2} X(B S F)
$$

Data analysis procedure: The data was checked for clarity and completeness, and it was analyzed by using password protected database for statistical analysis using a commercially available software SPSS version 21 of computer software. The data was processed by using descriptive analysis, including frequency distribution. Finally, the results of calculated ESDs for both $\mathrm{CR}$ and DR were compared with each other,and with internationally established Diagnostic Reference Levels (DRLs) and with similar studies conducted in different countries.

Ethical considerations: In order to respect the study group's bill of right, ethical considerations were taken into account. Clear and detailed explanations were given to the study population about the objective of the study. Any piece of information was kept confidential by not recording names of respondents.

\section{RESULTS}

The mean and range values of technical parameters $\mathrm{kVp}, \mathrm{mAs}, \mathrm{FSD}$ and patient related data (patient age, weight, BMI, and height) were documented in Table 1 and Table 2 for CR and DR examination, respectively. Out of 389 pediatric X-ray projections, 202 of them were taken with CR while 187 X-ray projections were taken with DR. As shown in Table 1, from a total of 202 CR X-ray projections, chest (AP) were 69(17.7\%), CXR -PA were $84(21.6 \%)$, Extremities AP were $27(6.9 \%)$ skull (AP) were 11(2.8\%), similarly, skull (PA) were $11(2.8 \%)$. As shown in Table 3 , from a total of 389 projections $231(54.9 \%)$ were chest (AP/PA) examinations. This is an indication that larger numbers of chest AP/PA pediatric X-ray examination were taken during the research period. The summary of entrance surface doses (ESDs) delivered to 389 X-ray projections undergoing three and four types of examinations for CR and DR respectively are documented in Table 3 . From this table, one can make a comparison of the dose levels among $\mathrm{CR}, \mathrm{DR}$, other countries and international dose levels. 
Table 1: The mean exposure parameters ( $\mathrm{kVp}, \mathrm{mAs}$ and FSD) for 6 types of pediatric diagnostic examinations with Different projections and for the use of CR

\begin{tabular}{|c|c|c|c|c|c|c|c|c|c|c|}
\hline \multirow[t]{2}{*}{ Examination } & \multirow{2}{*}{$\begin{array}{l}\text { Projection } \\
\text { (Numbe) }\end{array}$} & \multirow{2}{*}{$\begin{array}{c}\text { Sex } \\
(\mathbf{M} / \mathbf{F})\end{array}$} & \multirow{2}{*}{$\begin{array}{c}\text { Age } \\
\text { Group } \\
\text { in year }\end{array}$} & \multirow{2}{*}{$\begin{array}{l}\text { Patient age } \\
\text { in year } \\
\text { (Rang) }\end{array}$} & \multirow{2}{*}{$\begin{array}{l}\text { Patient Height } \\
\text { in (cm) } \\
\text { (Range) }\end{array}$} & \multirow{2}{*}{$\begin{array}{c}\text { Patient weight kilogram } \\
\text { (Range) }\end{array}$} & \multirow{2}{*}{$\begin{array}{l}\text { BMI in } \\
\left(\mathrm{kg} / \mathrm{m}^{2}\right) \text { Range }\end{array}$} & \multicolumn{3}{|c|}{ Radiographic data } \\
\hline & & & & & & & & KVp (Range) & $\begin{array}{c}\text { mAs } \\
\text { (Rang) }\end{array}$ & $\begin{array}{c}\text { FSD in (cm) } \\
\text { (Range) }\end{array}$ \\
\hline & & & $0-1$ & $0.4(0.03-0.91)$ & $65.6(40-93)$ & $6.2(1.1-11)$ & $13(6.8-19)$ & $46.3(40-57)$ & $8.02(6.3-10.2)$ & $93(93-93)$ \\
\hline \multirow[t]{4}{*}{ CXR } & $\mathrm{AP}=69$ & $M=44$ & $1-5$ & $2.9(1-4.8)$ & $80.8(50-110)$ & $12.3(1.2-22)$ & $20(8-36)$ & $64.9(46-81)$ & $13.6(0.1-213)$ & $110.6(60-139)$ \\
\hline & & $\mathrm{F}=25$ & $5-10$ & $6.1(5-9)$ & $100(75-130)$ & $17.6(11-24)$ & $18.8(10-31.7)$ & $75.3(60-80)$ & $20.5(0.4-63)$ & $124(59-132)$ \\
\hline & & & $10-15-$ & $14.4(12-15)$ & $165.4(155-173)$ & $53(45-64)$ & $19.5(15-25)$ & $71.4(68-81)$ & $12.9(6.8-20)$ & $117(87-137)$ \\
\hline & & & $0-1$ & -- & -- & -- & -- & -- & -- & -- \\
\hline \multirow[t]{4}{*}{ CXR } & $\mathrm{PA}=84$ & $\mathrm{M}=45$ & $1-5$ & $3.6(1-5)$ & $86.4(4-120)$ & $15(3-23)$ & $17(9-23)$ & $56.8(48-89)$ & $8.7(0.5-16.7)$ & $119(92-142)$ \\
\hline & & $\mathrm{F}=39$ & $5-10$ & $7.6(6-9)$ & $120.4(100-143)$ & $21.5(15-30)$ & $15(9.6-19)$ & $61.3(45-80)$ & $14.5(0.4-63)$ & $123.5(90-140)$ \\
\hline & & & $10-15$ & $13.1(10-15)$ & $143.8(80-170)$ & $37.2(20-58)$ & $18(13-39)$ & $63.3(50-80)$ & $12.6(0.4-33.3)$ & $124.6(89-139)$ \\
\hline & & & $0-1$ & -- & -- & -- & -- & -- & -- & -- \\
\hline \multirow[t]{4}{*}{ Extremities } & $\mathrm{AP}=27$ & $M=16$ & $1-5$ & $2(1-3.5)$ & $71.8(50-100)$ & $9.3(4-15)$ & $17(15-19)$ & $51.6(48-55)$ & $5.6(0.4-10.2)$ & $90(70-100)$ \\
\hline & & $\mathrm{F}=11$ & $5-10$ & $7(5-9)$ & $132(110-190)$ & $19(14-23)$ & $13.5(10-16.5)$ & $51.4(45-57)$ & $4(2.5-5)$ & $130(100-150)$ \\
\hline & & & $10-15$ & $12.6(10-15)$ & $129.7(110-155)$ & $32.4(17-51)$ & $18.6(10.5-24)$ & $50.3(45-75)$ & $3.3(2.5-7.9)$ & $130.6(100-150)$ \\
\hline & & & $0-1$ & -- & -- & -- & -- & -- & -- & -- \\
\hline \multirow[t]{4}{*}{ Skull } & $\mathrm{AP}=11$ & $M=6$ & $1-5$ & $2.7(1.3-5)$ & $78.7(55-100)$ & $11.1(8-14)$ & $19.5(12-36)$ & $72.4(70-75)$ & $16.8(1.5-25)$ & $88.5(85-90)$ \\
\hline & & $\mathrm{F}=5$ & $5-10$ & $7.5(6-10)$ & $105.3(85-150)$ & $24.3(18-40)$ & $22(18-28)$ & $72.3(60-85)$ & $18.1(10-31)$ & $82(68-88)$ \\
\hline & & & $10-15$ & -- & -- & -- & -- & -- & -- & -- \\
\hline & & & $0-1$ & -- & -- & -- & -- & -- & -- & -- \\
\hline \multirow[t]{3}{*}{ Skull } & $\mathrm{PA}=11$ & $M=7$ & $1-5$ & -- & -- & -- & -- & -- & -- & -- \\
\hline & & $\mathrm{F}=4$ & $5-10$ & $6.9(5-9)$ & $98.3(58-123)$ & $18.5(10-31)$ & $20(8-35)$ & $66.2(55-81)$ & $4.8(0.4-12.5)$ & $83(68-88)$ \\
\hline & & & $10-15$ & $12.2(10-14)$ & $122.8(110-138)$ & $31.4(24-40)$ & $21(16-24)$ & $62(58-72)$ & $4.7(0.6-6)$ & $85(81-86)$ \\
\hline
\end{tabular}

DOI: http://dx.doi.org/10.4314/ejhs.v30i2.15 
Table 2: The mean exposure parameters (kVp, mAs and FSD) for 6 types of paediatric diagnostic examinations with different projections and for the use of DR

\begin{tabular}{|c|c|c|c|c|c|c|c|c|c|c|}
\hline \multirow[t]{2}{*}{ Examination } & \multirow{2}{*}{$\begin{array}{l}\text { Projection } \\
\text { (Number) }\end{array}$} & \multirow{2}{*}{$\begin{array}{c}\text { Sex } \\
(\mathbf{M} / \mathbf{F})\end{array}$} & \multirow{2}{*}{$\begin{array}{l}\text { Age } \\
\text { Group } \\
\text { in year }\end{array}$} & \multirow{2}{*}{$\begin{array}{l}\text { Patient age } \\
\text { in year } \\
\text { (Range) }\end{array}$} & \multirow{2}{*}{$\begin{array}{l}\text { Patient Height } \\
\text { in }(\mathbf{c m}) \\
\text { (Range) }\end{array}$} & \multirow{2}{*}{$\begin{array}{l}\text { Patient weight } \\
\text { kilogram } \\
\text { (Range) }\end{array}$} & \multicolumn{4}{|c|}{ Radiographic data } \\
\hline & & & & & & & $\begin{array}{c}\text { BMI in } \\
\left(\mathrm{kg} / \mathrm{m}^{2}\right) \\
\text { Range } \\
\end{array}$ & KVp (Range) & $\begin{array}{c}\text { mAs } \\
\text { (Range) }\end{array}$ & $\begin{array}{c}\text { FSD in (cm) } \\
\text { (Range) }\end{array}$ \\
\hline \multirow{3}{*}{ CXR } & \multirow{3}{*}{$\mathrm{AP}=56$} & & $0-1$ & $0.4(0.03-0.9)$ & $55.5(40-75)$ & $5.3(7.5-8)$ & $18(11-32)$ & $55.9(40-80)$ & $3.5(1.6-6.3)$ & $99(87-107)$ \\
\hline & & $M=25$ & $1-5$ & $7.3(1-4)$ & $79.3(60-135)$ & $11.2(4.5-19)$ & $19(12.5-34)$ & $58(40-90)$ & $4.9(1.3-25)$ & $100.2(90-120)$ \\
\hline & & $\mathrm{F}=31$ & $5-10$ & $6.3(5-9)$ & $110.3(50-135)$ & $20.8(11-40)$ & $14(12-24)$ & $64.4(50-85)$ & $5.5(3.9-8)$ & $104.6(79-124)$ \\
\hline \multirow{4}{*}{ CXR } & \multirow{4}{*}{$\mathrm{PA}=22$} & & $10-15$ & $11.4(10-13)$ & $147.7(120-180)$ & $30(23-45)$ & $14(10-21)$ & $82(65-90)$ & $3.2(2-5.6)$ & $115.6(107-117)$ \\
\hline & & & $0-1$ & -- & -- & -- & -- & -- & -- & -- \\
\hline & & $M=8$ & $1-5$ & -- & -- & -- & -- & -- & -- & -- \\
\hline & & $\mathrm{F}=14$ & $5-10$ & $7.4(5-9)$ & $111.3(77-140)$ & $21.2(8-25)$ & $18(13-29)$ & $54.6(50-58)$ & $36(1.6-5.6)$ & $113.6(89-129)$ \\
\hline \multirow{4}{*}{ Extremities } & \multirow{4}{*}{$\mathrm{AP}=82$} & & $10-15$ & $12.6(10-15)$ & $139.7(70-170)$ & $36.6(8-46)$ & $19(14-34)$ & $67.2(60-90)$ & $6(2-20)$ & $127.9(87-137)$ \\
\hline & & & $0-1$ & -- & -- & -- & -- & -- & -- & -- \\
\hline & & $M=47$ & $1-5$ & $2.3(1-4)$ & $81.2(45-110)$ & $11.2(2-20)$ & $17(8-32)$ & $52.1(40-65)$ & $7.3(2-25)$ & $98.3(1.5-120)$ \\
\hline & & $\mathrm{F}=35$ & $5-10$ & $6.8(5-9)$ & $124.1(90-143)$ & $20.3(13-34)$ & $14(8-24)$ & $53.7(45-65)$ & $6.3(2.5-12.5)$ & $104.1(99-144)$ \\
\hline \multirow{5}{*}{ Skull } & \multirow{5}{*}{$\mathrm{AP}=9$} & & $10-15$ & $12.2(10-15)$ & $140.3(80-165)$ & $34.2(23-45)$ & $18(10-42)$ & $58.5(48-68)$ & $9(0.8-20)$ & 104(94-144) \\
\hline & & & $0-1$ & -- & -- & -- & -- & -- & -- & -- \\
\hline & & $M=3$ & $1-5$ & -- & -- & -- & -- & -- & -- & -- \\
\hline & & $\mathrm{F}=6$ & $5-10$ & $7(4-10)$ & $114.1(59-170)$ & $23(10-47)$ & $19(10-31)$ & $71.3(60-77)$ & $9.1(6.3-16)$ & $89.7(88-98)$ \\
\hline & & & $10-15$ & -- & -- & -- & -- & -- & -- & -- \\
\hline
\end{tabular}

Table 3: The comparison of mean exposure parameters of ESD in(mGy)DRL (third quartile value) for both CR, DR and with other studies and International publications for 6 different type of projection examinations. 


\begin{tabular}{|c|c|c|c|c|c|c|c|c|c|c|c|c|}
\hline \multirow{2}{*}{$\begin{array}{c}\text { Exam } \\
\text { nation }\end{array}$} & \multicolumn{4}{|c|}{ Projection and Total (Number) } & \multirow{2}{*}{$\begin{array}{c}\text { Age } \\
\text { Group } \\
\text { in year } \\
0-1\end{array}$} & \multicolumn{2}{|c|}{ DRL or $3^{\text {rd }}$ quartile of ESD (This study) } & \multirow{2}{*}{\multicolumn{2}{|c|}{$\begin{array}{c}\text { Ethiopia (2011) } \\
\text { Previous Study } \\
\text { BLH } \\
\text { YEK12H } \\
\end{array}$}} & \multirow[t]{2}{*}{ Iran 2018} & \multirow{2}{*}{$\begin{array}{c}\text { UNSCEAR } \\
(2000)\end{array}$} & \multirow{2}{*}{$\begin{array}{l}\text { IAEA } \\
(2001)\end{array}$} \\
\hline & \multicolumn{2}{|c|}{ For CR Sex (M/F) } & \multicolumn{2}{|c|}{ For DR Sex(M/F) } & & $\mathbf{C R}$ & DR & & & & & \\
\hline CXR & \multirow[t]{2}{*}{$\mathrm{AP}=69$} & \multirow[t]{2}{*}{$\begin{array}{l}M=44 \\
F=25\end{array}$} & $\mathrm{AP}=56$ & $\begin{aligned} M & =25 \\
\mathrm{~F} & =31\end{aligned}$ & $\begin{array}{c}0-1 \\
1-5 \\
5-10\end{array}$ & $\begin{array}{c}0.24 \\
0.3 \\
1.97\end{array}$ & $\begin{array}{l}0.15 \\
0.16 \\
0.26\end{array}$ & $\begin{array}{l}0.104 \\
0.109 \\
0.119\end{array}$ & $\begin{array}{c}0.2 \\
0.253 \\
0.281\end{array}$ & - & $\begin{array}{l}0.02 \\
0.03 \\
0.04\end{array}$ & $\begin{array}{l}0.05 \\
0.07 \\
0.12\end{array}$ \\
\hline \multirow{5}{*}{ CXR } & & & \multirow{5}{*}{$\mathrm{PA}=22$} & & $10-15$ & 0.56 & 0.18 & 0.108 & -- & & 0.05 & -- \\
\hline & \multirow{4}{*}{$\mathrm{PA}=84$} & \multirow{4}{*}{$\begin{array}{l}M=45 \\
F=39\end{array}$} & & & $0-1$ & -- & -- & -- & -- & 0.06 & 0.02 & 0.05 \\
\hline & & & & $M=8$ & $1-5$ & 0.28 & -- & -- & -- & 0.16 & 0.03 & 0.07 \\
\hline & & & & $\mathrm{F}=14$ & $5-10$ & 0.53 & 0.1 & 0.411 & 0.332 & 0.38 & 0.04 & 0.12 \\
\hline & & & & & $10-15$ & 0.54 & 0.15 & 0.804 & 0.39 & 0.54 & 0.05 & -- \\
\hline \multirow{3}{*}{ Extremities } & \multirow{4}{*}{$\mathrm{AP}=27$} & \multirow{4}{*}{$\begin{array}{l}M=16 \\
F=11\end{array}$} & \multirow{4}{*}{$\mathrm{AP}=82$} & \multirow{4}{*}{$\begin{array}{l}M=47 \\
F=35\end{array}$} & $0-1$ & -- & -- & -- & -- & -- & -- & -- \\
\hline & & & & & $1-5$ & 0.22 & 0.248 & -- & -- & -- & -- & -- \\
\hline & & & & & $5-10$ & 0.13 & 0.19 & -- & -- & -- & -- & -- \\
\hline \multirow{5}{*}{ Skull } & & & & & $10-15$ & 0.09 & 0.41 & -- & -- & -- & -- & -- \\
\hline & \multirow{4}{*}{$\mathrm{AP}=11$} & \multirow{4}{*}{$\begin{array}{l}M=6 \\
F=5\end{array}$} & \multirow{4}{*}{$\mathrm{AP}=9$} & \multirow{4}{*}{$\begin{array}{l}M=3 \\
F=6\end{array}$} & $0-1$ & -- & -- & 0.389 & 0.513 & 0.51 & 0.15 & 0.8 \\
\hline & & & & & $1-5$ & 1.5 & -- & 1.125 & 0.834 & 0.75 & 0.48 & 1.1 \\
\hline & & & & & $5-10$ & 2.2 & 1.7 & 1.159 & 1.428 & 0.93 & 0.73 & 1.1 \\
\hline & & & & & $10-15$ & -- & -- & 1.52 & 3.189 & 1.22 & 0.94 & 1.1 \\
\hline \multirow{3}{*}{ Skull } & \multirow{3}{*}{$\mathrm{PA}=11$} & & & & $0-1$ & -- & -- & -- & -- & 0.51 & -- & 0.8 \\
\hline & & $M=7$ & $\mathrm{PA}=9$ & $M=5$ & $1-5$ & 0.16 & -- & -- & -- & 0.75 & -- & 1.1 \\
\hline & & $\mathrm{F}=4$ & & $\mathrm{~F}=4$ & $5-10$ & 0.18 & -- & -- & -- & 0.93 & -- & 1.1 \\
\hline & & & & & $10-15$ & -- & -- & -- & -- & 1.22 & -- & 1.1 \\
\hline & & & & & $0-1$ & -- & -- & -- & 0.265 & 0.47 & 0.07 & 0.5 \\
\hline Pelvis & $\mathrm{AP}=$ & $\mathrm{M}=$ & $\mathrm{AP}=18$ & $\mathrm{M}=13$ & $1-5$ & -- & 0.88 & 0.253 & 0.377 & 0.91 & 0.08 & 0.6 \\
\hline & & $\mathrm{F}=$ & & $\mathrm{F}=5$ & $5-10$ & -- & 1.6 & 0.435 & 1.117 & 1.23 & 0.04 & 0.7 \\
\hline & & & & & $10-15$ & -- & -- & 1.438 & 1.785 & 1.51 & 1.13 & 2 \\
\hline
\end{tabular}




\section{DISCUSSION}

The findings of the study revealed that the mean applied tube loading using $\mathrm{CR}$ examination for each examination to be higher than the corresponding mean values reported in DR examination undertaken. Similarity, the CR mean ESDs received by patients for chest AP/PA pediatric-ray were very much higher than DR and the corresponding values noted in other counties and in international diagnostic reference levels.

The tube potential $\left(\mathrm{kV}_{\mathrm{p}}\right)$, tube loading $(\mathrm{mAs})$ and film focus distance (FFD) were the major radiographic parameters that can determine the level of radiation dose delivered to patients subjected to a specific radiographic examination. During exposure, the tube voltage controls the mean and peak X-ray energies in the X-ray beam. Low kilo-voltages, giving lower energy X-rays, leads to higher skin doses for patients (8-10) while the tube loading (mAs) controls the quantity of the X-rays delivered to the patient. A high $\mathrm{mAs}$ means large number of X-rays are produced within the X-ray tube that causes a high ESD for patients. Increasing FFD significantly reduces radiation doses without affecting image quality (11). Therefore, a proper use of these parameters by radiographers is very important in order to optimize radiological practice and protect patients from unnecessary radiation dose. In this study, the skull AP from (5-10) year-group for both CR and DR and the pelvis AP for the (1-5) and (5-10) year-groups for DR $\mathrm{X}$-ray examination had higher ESD.These values were higher than previous Ethiopian studies (9), as well as international ones like UNSCEAR (2), Iran (12) and IAEA (13) studies. Similarly, pelvis AP (1-5) and (5-10) years for DR X-ray examination have higher ESD than $(2,9,12,13,14)$ similar studies. Surprisingly, the entrance surface doses received with CR extremities examination were less than that of DR X-ray examination. This is explained by the fact that less $\mathrm{mAs}$ and high focus skin distance (FSD) were employed with CR than DR examination. Patient size is one of the important factors affecting the variability of entrance surface dose (ESD) as documented by (8). Hence, in both CR and DR, as patient weight increases, ESD dose increases, except for (10-15) years in both X-ray examinations.

The study also demonstrated that the lowest and highest entrance surface dose values for chest (AP) X-ray examination were higher for CR than DR. From these, one can infer that patients undergoing chest (AP) X-ray examination at $\mathrm{CR}$ were exposed to a high ESDs compared to those at DR. The possible explanation for this may be the use of low mAs in DR than those recorded at $\mathrm{CR}$. This $\mathrm{CR}$ entrance surface dose value is much higher than the dose reference levels recommended by a previous study in Ethiopian (9), UNSCEAR (2000) (2), Iran (2018) (12) and IAEA (2001) (13). The use of optimal tube potential and tube loading in chest radiography has received a considerable amount of discussion in the radiological literature (1518). It has been shown that increasing the tube potential in chest radiography from $60 \mathrm{kV}_{\mathrm{p}}$ to $90 \mathrm{kV}_{\mathrm{p}}$ will result in an Entrance Surface Dose (ESD) saving of $60 \%$ (18, 19).

Also the use of high tube voltage and low tube loading techniques for the X-ray examination has been calculated to reduce effective dose by many researchers $(19,20)$. Therefore, the use of low tube potentials should be discouraged. In the present study, in general, the predominant use of low tube potentials $\left(\mathrm{kV}_{\mathrm{p}}\right)$ and high tube loadings (mAs) were likely to be the major factors that contributed to the high entrance surface doses (ESDs) received by patients undergoing chest (AP/PA) and pelvis X-ray examinations in the seven hospitals/clinics as compared to the dose reference levels (DRLs) recommended by international organizations. The results of the study revealed that majority of the patients received entrance surface dose in unacceptable range. This is an indication that nonoptimized radiological practices were employed in the study area for X-ray examinations. The major contributor to the high doses reported in this work has been identified to be the use of radiographic parameters that are inconsistent with the international guidelines and other studies (20). Although the mean ESDs were found to be much higher than the corresponding recommended DRLs and other studies for chest examinations, this does not mean that dose levels could not be reduced without loss of diagnostic information by improving the radiographic techniques used. Considerable dose variations for the same type of X-ray examination strongly support the idea that further optimization is possible. For example, the loading factors extend from 45 to $80 \mathrm{kV}_{\mathrm{p}}$ and from 0.4 to $63 \mathrm{mAs}$ for PA chest radiography taken with $\mathrm{CR}$ for (5-10) years is one of the reasons for the variation of doses to patients. The finding from these results shows that significant reductions in patient doses would be possible in CR without adversely affecting image quality. Therefore, the result of this study suggests a need for optimization of radiological parameters in $\mathrm{CR}$ to avert pediatric patient doses.

\section{ACKNOWLEDGEMENTS}

We gratefully acknowledge the financial support of Addis Ababa University and International Center for Theoretical Physics. Our gratitude also goes to all the

DOI: http://dx.doi.org/10.4314/ejhs.v30i2.15 
hospitals that participated in this study and their staff for their cooperation.

\section{REFERENCES}

1. Rana BS, Kumar S, Sandhu IS, Singh NP. Dosimetry of adult and pediatric patients for common digital radiography examinations. Radiation Protection Dosimetry: 2018;179(4):349-357. doi: 10.1093/rpd/ncx293

2. United Nations Scientific Committee on the Effects of Atomic Radiation Sources:Sources and effects of ionizing radiation. UNSCEAR 2000 Report to the General Assembly, with Scientific Annexes. UNITED NATIONS New York, 2000

3. SadekaSR, Shakilur R, Santunu P, Kawchar AP, Moinul HM , Mamun AA.Measurements of Entrance Surface Dose and Effective Dose of Patients in Diagnostic Radiography. Biomed J Sci \& Tech Res,2018: 12(1):8924-8928. DOI: 10.26717/BJSTR.2018.12.002186

4. Elena T, Cupido D,Mary J. et.al. Diagnostic Reference Levels for Typical Radiographic Procedures. Canadian Association of Radiologists Journal, 2012:63: 237-241.

5. John E, EmerencianaD, Pat D, John R. Optimization of Dose and Image Quality for Computed Radiography and Digital Radiography. Journal of Digital Imaging, 2006:19(2): 126-131.

6. WambaniS, Korir GK, Korir IK, Kilaha S. Establishment of local diagnostic reference levels in paediatric screen-film radiography at a children's hospital: Radiation Protection Dosimtetry:2013:154(4):465-476.

7. Hart D, HillierMC, WallBF. National reference doses for common radiographic, fluoroscopic and dental x-ray examinations in the UK. Br J Radiol, 2009; 82(973): 1-12.

8. Bushra E, Sulieman A,Osman H.Radiation Measurement and Risk Estimation for Pediatric Patients during Routine Diagnostic Examination in some hospitals of Khartoum state:Tenth Radiation Physics \& Protection Conference: 2010: Nasr City - Cairo, Egypt

9. Seife T, Daniel A,Tekle A,Durga PR: Entrance Surface Dose Measurement In Pediatric Patients Undergoing Common Diagnostic X-ray Examinations in Black Lion and Yekatit 12
Hospital Addis Ababa ,Ethiopia.Ethiop Med J, 2011: 49(1):51-60.

10. SulimanN.,HabbaniFI.Entrance surface doses to patients undergoing selected diagnostic X-ray examinations in Sudan. Radiat. Prot. Dosim, 2007;123(2): 209-214.

11. Karami V, Zabihzadeh M, Shams N. Optimization of Radiological Protection in Pediatrics Undergoing Common Diagnostic X-ray Procedures: Effectiveness of Increasing the Film to Focus Distance (FFD). Int J Pediatr,2017; 5(4): 4771-82.

12. MohsenzadehB, Deevband MR, Pouriran R. The National Diagnostic Reference Level in Routine Digital Radiography Examinations in Iran. Biomedical Journal of Scientific \& Technical Research, 2018; 7(5):1-10.

13. IAEA, 2001. Radiological protection of patients in diagnostic and interventional radiology, nuclear medicine and radiotherapy. IAEA, Vienna, 2001 IAEA-CSP-7/P ISSN 1563-0153

14. Karami V, zabihzadeh $M$. Evaluation of the Entrance Surface Dose (ESD) and Radiation Dose to the Radiosensitive Organs in Pediatric Pelvic Radiography. International Journal of Pediatrics,2017; 5(5):5013-22.

15. Jochen B, Robert N, Peter H. Diagnostic reference levels in pediatric radiology in Austria. EurRadiol,2010; 20: 1572-1579. DOI 10.1007/s00330-009-1697-7

16. CEC, 2008. European guidance on estimating population doses from medical X-ray procedures. Radiation Protection Publication No 154.

17. Annals: Radiological protection in pediatric diagnostic and interventional radiology of the ICRP: 2011

18. PiDRL Guidelines, European Guidelines on DRLs for PaediatricImaging:,Final complete draft for PiDRL Workshop: September 2015

19. De SL, Silva TA, Khoury HJ. Assessment of dosimetric quantities for patients undergoing Xray examinations in a large public hospital in Brazil -A preliminary study. Radiation Protection Dosimetry, 2008; 132 (1): 73-79.

20. European Community. European guidelines on quality criteria for diagnostic radiographic images. Report EUR 16260EN 1996; (Luxemburg: Office for Official Publication of the European Community). 